CASE REPORT

\title{
Nodules of fibrocollagenous scar tissue induced by subcutaneous insulin injections: a cause of poor diabetic control
}

\author{
M E Wallymahmed, P Littler, C Clegg, M T Haqqani, I A MacFarlane
}

Postgrad Med J 2004;80:732-733. doi: 10.1136/pgmj.2004.019547

\begin{abstract}
A 46 year old man with longstanding type 1 diabetes developed major weight loss and marked deterioration in diabetic control. He had been persistently injecting insulin into areas of abdominal lipohypertrophy within which hard collagenised fibrous tissue nodules had developed. Injecting insulin at different sites dramatically improved blood glucose control. Fibrocollagenous nodules induced by insulin injections have not been previously described. Examination of a further 73 type 1 patients revealed lipohypertrophy in $44 \%$ and hard subcutaneous nodules on two.
\end{abstract}

nsulin injections can cause a variety of subcutaneous changes, particularly if patients do not rotate sites. This

includes lipohypertrophy, lipoatrophy, ${ }^{1-2}$ and rarely infections. The extensive use of human insulin has reduced the prevalence of lipoatrophy but lipohypertrophy remains a significant clinical problem occurring in $27-48 \%$ of patients. ${ }^{1-3}$ Lipohypertrophy can lead to erratic insulin absorption ${ }^{4}$ and is unsightly.

There are few reports of injection site problems in the recent literature. We report a case of a previously undescribed phenomenon of bilateral large hard subcutaneous nodules at abdominal wall injection sites. Examination of 73 further patients with type 1 diabetes revealed lipohypertrophy in many cases, two of whom had also developed hard subcutaneous nodules.

\section{CASE REPORT}

A 46 year old man with type 1 diabetes of 24 years' duration presented with an abscess on his scalp. There had been a weight loss of $11 \mathrm{~kg}$ and worsening diabetic control (glycated haemoglobin (HbAlc) increased from $10.6 \%$ to $16.5 \%$ ) despite increased insulin dose over the past 12 months. He had a history of microalbuminuria, peripheral neuropathy, background retinopathy, cerebrovascular disease, and hypertension and was taking Human Mixtard 30 insulin 26 units twice daily. For years he had given all his insulin injections into the abdominal wall. He had bilateral $8 \times 8 \mathrm{~cm}$ areas of typical lipohypertrophy (see fig 1) which both contained "woody hard" smooth $4 \mathrm{~cm}$ diameter nodules that felt like golf balls. He said he always injected insulin into these nodules. Biopsies of the core portion of one of the lesions revealed dense hypocellular and hypovascular collagen with bland looking fibroblasts and foci of necrosis. The appearance was that of collagenous scar tissue. There was no evidence of amyloid.

Rotation of injection sites, avoiding the nodules and areas of lipohypertrophy was advised. By three months glycaemic control had improved (HbAlc 9.7\%), his weight had increased by $10 \mathrm{~kg}$, and insulin dose had reduced to 38 units daily. The areas of lipohypertrophy had reduced to $2.5 \times$ $2.5 \mathrm{~cm}$ and the nodules were much smaller and softer.

\section{AUDIT OF INJECTION SITES}

The injection sites of 73 other consecutive patients with type 1 diabetes (48\% male), mean age 31 years, mean duration of diabetes 13.6 years, and mean HbAlc 9.5\% were examined. Thirty three patients (45\%) had not had their injection sites examined at their last annual review. The majority of patients (42) stated that they rotated insulin injection sites on a regular basis, while 31 patients tended to stick to one main area, although rotation within that area was reported. The most common sites for insulin injections were the legs and abdomen. A total of 32 patients (44\%) had clinical lipohypertrophy (arms $41 \%$, legs 31\%, more than one site $28 \%$ ). Twenty five were graded as diffuse, five as minor induration, and two patients had hard nodular lumps within hypertrophied areas (one abdominal and one thigh). One of these patients had very poor diabetic control (HbAlc 14.6\%) and recent weight loss and also admitted injecting repeatedly into the hard nodules. There was no significant difference in HbAlc between those with lipohypertrophy and those without $(9.6 \% \vee 9.5 \%)$. Mean (SD) duration of diabetes was significantly longer in those with lipohypertrophy than those without (17.2 (9.2) $v 11$ (7.1) years, $\mathrm{p}<0.02)$.

All three patients with hard nodules (including the index case) were currently injecting human insulin.

\section{DISCUSSION}

Previous studies of insulin injection sites have not reported discrete large hard nodules of fibrocollagenous scar tissue, although there is one report of a hard thigh nodule containing amyloid. ${ }^{5}$ Our audit identified a further two patients with similar hard nodules, both had poor diabetic control (HbAlc $14.4 \%$ and $11.1 \%$ ), and one had weight loss similar to the index case. It is reasonable to assume that

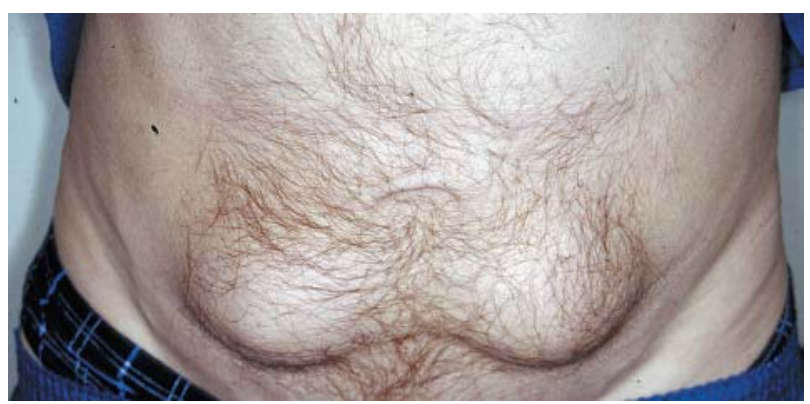

Figure 1 Abdominal wall injection sites showing bilateral areas of lipohypertrophy which contained hard "golf balls" of fibrocollagenous scar tissue. 


\section{Learning points}

- Lipohypertrophy is a common complication of subcutaneous insulin therapy.

- Hard fibrocollagenous nodules can occasionally be found in areas of lipohypertrophy and can be associated with poor diabetic control.

- Patients should be advised to rotate injection sites preferably avoiding the same patch of skin for a month.

- Injection sites should be examined at least annually and more frequently if diabetic control deteriorates.

repeated trauma of localised subcutaneous injections may lead to fat necrosis and then nodules of fibrocollagenous scar tissue. These nodules would not be very vascular and injecting into them would lead to impaired insulin release and poor diabetic control. In our index patient there was a marked improvement in glycaemic control and weight gain after rotation of insulin injection sites and the hard collagen nodules shrank. All three patients with hard nodular lumps admitted to injecting all insulin injections into the nodules mainly due to habit and comfort despite being previously informed of the importance of rotation of insulin sites. Interestingly the abdominal nodules were only noticeable to the two patients after a rapid weight loss and were more apparent when standing up. Injection site lipohypertrophy remains a significant problem in our clinic population with $44 \%$ of patients surveyed having some degree of lipohypertrophy. Previously reported prevalence rates vary from $27 \%-48 \%{ }^{1-2}$ with higher rates reported in type 1 diabetes than type 2 insulin treated diabetes. ${ }^{6}$ As with several previous studies we did not find any significant difference in glycaemic control between those with lipohypertrophy and those with no lipohypertrophy. ${ }^{16}$ Lipohypertrophy was associated with a longer duration of diabetes and it is possible that some of these patients would have been initially treated with animal insulins. It is disappointing that nearly half of our patients $(45 \%)$ had not had their injection sites examined at the last annual review, although this is recommended. ${ }^{7}$
Many of our patients with lipohypertrophy were aware of the importance of rotating insulin injections sites but cited habit as the main reason they continued to inject into the same area. Avoidance of sites with lipohypertrophy has been shown to improve glycaemic control, ${ }^{89}$ therefore repeated advice on the organised rotation of insulin sites needs to be built into patient education programmes. ${ }^{10}$ Persistent injections into areas of lipohypertrophy can lead to fibrocollagenous scar tissue "golf balls" and cause major deterioration in diabetic control.

\section{Authors' affiliations}

M E Wallymahmed, P Littler, C Clegg, M T Haqqani, I A MacFarlane, University Department of Diabetes and Endocrinology, University Hospital Aintree, Liverpool, UK

Correspondence to: Mrs Maureen Wallymahmed, Diabetes Centre, University Hospital Aintree, Rice Lane, Liverpool L91AE, UK; maureen. wallymahmed@aht.nwest.nhs.uk

Submitted 27 January 2004

Accepted 19 April 2004

\section{REFERENCES}

1 McNally PG, Jowett NI, Kurinczuk JJ, et al. Lipohypertrophy and lipoatrophy complicating treatment with highly purified bovine and porcine insulins. Postgrad Med J 1988:64:850-3.

2 Kordonouri O, Lauterborn R, Deiss D. Lipohypertrophy in young patients with type 1 diabetes. Diabetes Care 2002;25:634.

3 Strauss K. De Gols H, Hannet I, et al. A pan-European epidemiological study of insulin injection technique in patients with diabetes. Practical Diabetes International 2002; 19:71-6.

4 Thow JC, Johnson AB, Marsden S, et al. Morphology of palpably abnormal injection sites and effects on absorption of isophane (NPH) insulin. Diabet Med 1990;7:795-9.

5 Swift B, Hawkins PN, Richards C, et al. Examination of insulin injection sites: an unexpected finding of localized amyloidosis. Diabet Med 2002;19:881-2.

6 Hauner H, Stockamp B, Haastert B. Prevalence of lipohypertrophy in insulintreated diabetics and predisposing factors. Exp Clin Endocrinol Diabetes 1996; 104:106-10.

7 Diabetes UK. What diabetes care to expect. London: Diabetes UK, 2002.

8 Burden AC, Jones GR, Blandford RL. Insulin injection technique and diabetic control. Practical Diabetes 1984;1:10-12.

9 Chowdhury TA, Escudier V. Poor glycaemic control caused by insulin induced lipohypertrophy. BMJ 2003;327:383-4.

10 Saez-de Ibarra, Gallego F. Factors related to lipohypertrophy in insulintreated diabetic patients: role of educational intervention. Practical Diabetes International 1998;15:9-11. 